\title{
Packaged Software Application Services Industry: Evolution and the factors affecting the industry
}

\author{
Dr. K. Rangarajan ${ }^{1}$, Sushil K. Tiwari ${ }^{2}$ \\ ${ }^{I}$ (Prof. \&Head, Indian Institute of Foreign Trade, India) \\ ${ }^{2}$ (Research Scholar, Indian Institute of Foreign Trade, India)
}

\begin{abstract}
The global Software \& Services industry group is composed of the Information Technology and Communication markets. Information Technology consists of Services, Software, Digital Media and Hardware. Software consists of Software Development. And, in turn, the Package Applications Industry falls under Software Development. Package Applications Industry is divided into three segments -Applications Development \& Deployment, Applications, and System Infrastructure Software.

Though the package software industry forms a big chunk of the software services industry, there has been very little academic work done that are specifically related to this field. This paper tries taking a look at the way this industry has evolved, current status, future prospects, and key players in the industry etc.

The paper also lists down the factors influencing the package software industry through the secondary literature reviews and interviews with industry experts in the area. In the end, the paper recommends the possible approach for further research in the area.
\end{abstract}

Keywords: information technology, package software,standardization, influencing factors, dynamic

environment

\section{Introduction}

During the early years of commercial use of computers, all software systems were developed in-house from scratch using various development platforms ${ }^{l}$. Subsequently, software products were exclusively developed as unique systems for each organization and there was very little standardization.

The next phase of software evolution saw the growth of proprietary software widely called as 'Packaged software' with the objective to capture economies of scale in developing the software once and then selling it to multiple customers. This standardization process also benefitted software buyers by lowering transaction costs and risks, as it was possible to choose among a proven set of applications. As a win-win for both, standardization gave producers and buyers of software a way to capture and black-box best practices by embedding them into the standardized components of the systems.

Technically Packaged software is a category of information system for which all implementations are essentially identical and generally termed as 'template' or 'core business model.' Meaning, the main functionalities are common to all adopters. While the core components of a package are identical across all user organizations, the implementation into an individual organization is usually configured in a manner to fit the requirements of the local organization and is termed as 'Localization.'

Packaged software is also referred to as "commercial off-the-shelf" software. Open source systems or other types of nominally free software are other examples of packaged software. Some standard software packages require little or no configurations on the part of the user before they can perform, while other software packages provide basic features on top of which specific functionalities required by the user can be configured or customized.

Gartner studies ${ }^{2}$ have implicated that between 50 and 80 percent of IT budgets arespent on system implementation and maintenance and not on acquisition of software and hardware. Therefore, software licenses usually only include fraction of the total costs of enterprise solutions. In addition, maintaining and running enterprise applications usually requires considerable amount of IT resources from underlying firms. All these facts contribute to the total costs of enterprise solutions for the acquiring companies, and are naturally the characteristics of traditional models of packaged software.

Packaged software services industry has been constantly expanding and forms a major part of the IT services industry. These services are provided by the product vendors themselves as well as by a number of system integrators (SIs) who can also be termed as Package Software Application Services Vendors (PSASVs). These PSASVs operate in a very complex stakeholder environment. On one hand, they have to depend on the product vendors for the product related developments and issues resolution. And, on the other hand, they have to influence the customer in selecting a product and then helping the customer to implement and manage the application. Extremely dynamic business environment adds to the complexity in strategy formulation for the PSASVs. 
There is very little research literature available in the field of Package Software services. This paper is an attempt to give some fillip to further research in this area.

II. Performance Of The Packaged Services Industry

Package software industry is slated to register a CAGR of 6.3\% for the period of 2010-15 with revenue of staggering USD 376.5 billion in 2012 .

Table: 1Package Service industry value ${ }^{3}$ : $\$$ billion, $2010-15$

\begin{tabular}{ccc}
\hline Year & \$ billion & \% Growth \\
\hline 2010 & 316.0 & $\ldots$ \\
2011 & 331.5 & $4.91 \%$ \\
2012 & 352.7 & $6.39 \%$ \\
2013 & 376.5 & $6.74 \%$ \\
2014 & 402.3 & $6.85 \%$ \\
2015 & 430.9 & $7.11 \%$ \\
\hline \hline CAGR: 2010-15 & & $6.30 \%$ \\
\hline
\end{tabular}

The Americas continue to be the leader in package software business followed by Europe-Middle EastAfrica (EMEA) and Asia pacific-Japan (APJ) respectively (Fig: 1).

Fig: 1, Worldwide Packaged Software Revenue by Region ${ }^{3}$, 2011 - 2016

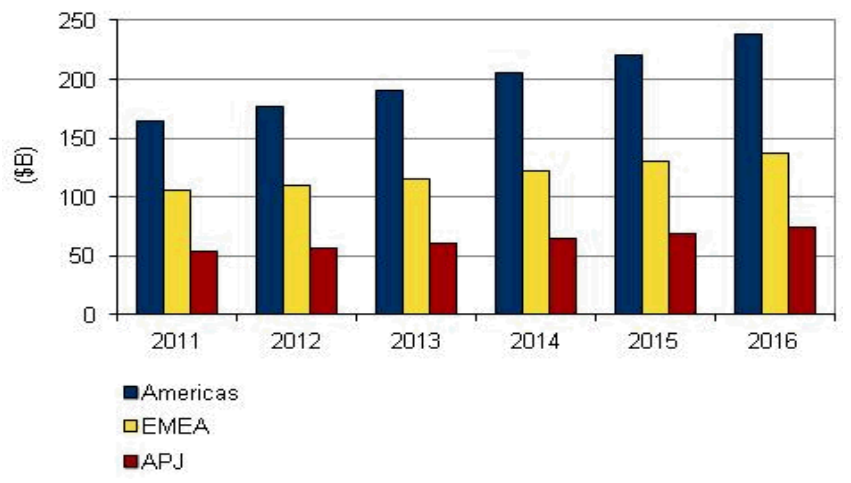

List below shows the 'geographical coverage' of the countries by the package software application services vendors. It may be the case that not all the vendors support all the countries but as a combination all the mentioned countries are covered.

North America (NAM): U.S., Canada.

Latin America (LATAM): Argentina, Bolivia, Brazil, Chile, Colombia, Costa Rica, Ecuador, Guatemala, Mexico, Panama, Peru, Uruguay, Venezuela.

Asia/Pacific and Japan (APJ): Australia, Bangladesh, China, Hong Kong, India, Indonesia, Japan, Korea, Malaysia, New Zealand, Pakistan, Philippines, Singapore, Sri Lanka, Taiwan, Thailand, Vietnam.

Europe, the Middle East and Africa (EMEA): Austria, Algeria, Azerbaijan, Bahrain, Belarus, Belgium, Bulgaria, Cameroon, Cote d'Ivoire, Croatia, Czech Republic, Denmark, Egypt, Finland, France, Germany, Greece, Hungary, Iceland, Ireland, Israel, Italy, Jordan, Kazakhstan, Kenya, Kuwait, Lebanon, Libya, Lithuania, Luxembourg, Morocco, Netherlands, Nigeria, Norway, Oman, Poland, Portugal, Qatar, Romania, Russia, Saudi Arabia, Serbia, Slovakia, Slovenia, South Africa, Spain, Sweden, Switzerland, Syria, Tunisia, Turkey, Ukraine, United Arab Emirates, United Kingdom, Yemen.

\section{Product Portfolio In Packaged Software Industry}

Customizable Package applications have a very wide range of product portfolio spreading across the operational to Business Intelligence to Relationship application packages as indicated below.

1.1 Operational Application Packages: These packages provide the functionalities to manage the day to day operations of the organization. These are in the areas of Sales and Distribution, Materials management, Production planning, Finance, Human resource management etc. SAP, PeopleSoft, Oracle Applications, JD Edwards, QAD, Manugistics, i2 are the examples. 
1.2 BI Application Packages: These packages mainly provide the data warehouse, analytics and reporting capabilities to the enterprises. The examples are Cognos, Microstrategy, Informatica, MS SQL Server Analysis Pack, SAP Business Intelligence, Hyperion Solutions Platforms etc.

1.3 Relationship Application Packages: These are mostly the customer facing applications for the enterprise. These are Kana Platform, Ariba, Microsoft CRM, Epiphany, CommerceOne, PeopleSoft CRM, Siebel Platforms, SAP CRM etc.

The figure below reflects the market share of various product vendors in the area of packaged software. It clearly shows that the market is highly fragmented. Top four vendors account for $40 \%$ of the market share. Fig: 2, Market share for the Package Software Vendors

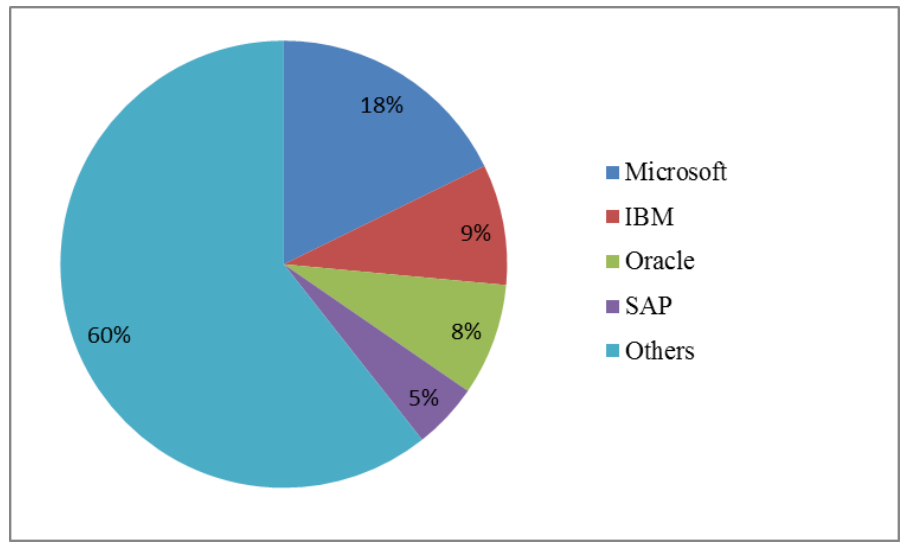

\section{Key Players In Package Software Application Services}

Most of the large Software System Integrators (SIs) in the market provide the package application services. Gartner magic quadrant though applies to SAP, but, is a good representative of the key players in the market as most of the players operate in multiple packaged products.

Gartner magic quadrant maps the services providers on two aspects - one, their completeness of vision, and, two, their ability to execute.Service providers falling in the Leaders quadrant are found to have completeness of vision as well as ability to execute. Accenture and IBMlead here followed by Indian players Infosys and TCS.Deloitte, though having completeness of vision to a great extent, but, having limited ability to execute, lands in the Visionaries quadrant. Challengers have the ability to execute but can do better on the vision side. HCL and Wipro among Indian players find the place here.Niche players are the service providers that are either operating at smaller levels by choice or have started building their package application practice later than their peers.

Fig: 3, Garter Magic Quadrants for packaged application services (SAP)

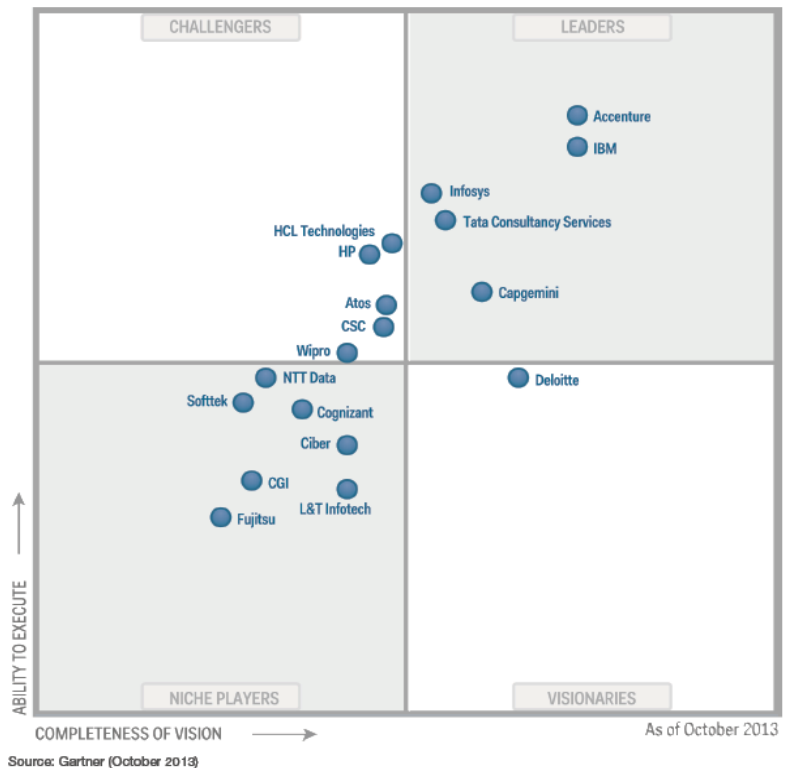




\section{Factors Affecting The Industry:}

The strategy and operations of package software application services vendors are influenced by two sets of factors. The first sets of factors are internal to the organization. The other set of factors are dependent on external entities and are mostly out of control for the services vendor organization. Based on the secondary literature reviews and interviews with the industry experts, the broad areas that affect the package software services vendors' strategy formulations turn out to beenvironment, financials, people, processes, structure, governance and technology etc. Explicit influencing factors coming out of the literature are indicated below.

Table: 2 Factors influencing the Strategy formulation and working of the Packaged Software Application Services Vendors

\begin{tabular}{|c|c|c|c|}
\hline No. & Factor & Area & Influencing factors \\
\hline 1 & \multirow{9}{*}{ Internal } & Environment & Financial considerations (Cost, Profitability etc. $)^{5}$ \\
\hline 2 & & People & Skill development $^{6}$ \\
\hline 3 & & Process & Pre-sales solutions ${ }^{7}$ \\
\hline 4 & & \multirow{3}{*}{$\begin{array}{l}\text { Structure / } \\
\text { Governance }\end{array}$} & Accessibility (Multi locations Operations) $^{8}$ \\
\hline 5 & & & Geographical Locations $^{8}$ \\
\hline 6 & & & Organization structure $^{9}$ \\
\hline 7 & & \multirow{3}{*}{ Technology } & Customization and Development Process $^{10}$ \\
\hline 8 & & & Innovation $^{11}$ \\
\hline 9 & & & Product Related Factors (Quality, Variety etc.) ${ }^{12}$ \\
\hline 10 & \multirow{16}{*}{ External } & \multirow{7}{*}{ Environment } & Economic Conditions and Business Environment ${ }^{13}$ \\
\hline 11 & & & Government Regulations, Legislations and Policy ${ }^{13}$ \\
\hline 12 & & & Industry Dynamics $^{14}$ \\
\hline 13 & & & Local Issues $^{15}$ \\
\hline 14 & & & Mergers and Acquisitions ${ }^{16}$ \\
\hline 15 & & & Other markets and players ${ }^{17}$ \\
\hline 16 & & & Social and Demographic Factors ${ }^{17}$ \\
\hline 17 & & Financials & Licensing Costs ${ }^{18}$ \\
\hline 18 & & People & Cultural Issues and Knowledge Gap ${ }^{19}$ \\
\hline 19 & & \multirow{2}{*}{ Process } & Changes in the sales process ${ }^{20}$ \\
\hline 20 & & & Product Process $^{21}$ \\
\hline 21 & & \multirow{3}{*}{$\begin{array}{l}\text { Structure / } \\
\text { Governance }\end{array}$} & $\begin{array}{l}\text { Globalization related factors (World class IT, } \\
\text { Knowledge of English etc.) }\end{array}$ \\
\hline 22 & & & Role of Industry organization i.e. NASSCOM ${ }^{23}$ \\
\hline 23 & & & $\begin{array}{l}\text { Structure and Governance (Alliances, Partnership, } \\
\text { Vendors etc.) }\end{array}$ \\
\hline 24 & & \multirow{2}{*}{ Technology } & Data Protection $^{24}$ \\
\hline 25 & & & Technology $y^{25}$ \\
\hline
\end{tabular}

\section{Suggestions For Further Research And Methodology}

Identified factors in Section V influencing Package Software Application Services Vendors may form the independent variables set for further research. Objective of the further research can be to

1. Study the inter-relationship of variables in the service creation and delivery.

2. Prepare the generic value chain of such firms and identify the weak areas in the current value chain of such PSASVs.

3. Understand the competitive forces in the industry and the trends in competitive dynamics leading to strategic responses.

4. Study the value chains of select firms to understand the value proposition, value creation and value delivery of services. 
5. Develop a conceptual strategy framework for the PSASVs which help formulate and implement strategies for value enhancement.

Researching strategy formulation and implementation for dynamic environment like Packaged software application services requires the right balance between quantitative and qualitative methods. ${ }^{26} \mathrm{~A}$ contingent research approach identifies such a balance. Statistical analysis can be leveraged to arrive at the relevant independent variables out of the variables coming out of the literature review. Output may be run iteratively through the case studies to arrive at the final set.

Using this approach, the degree to which quantitative and qualitative studies could be utilized would depend on the dynamics of change. In highly dynamic cases, research focusses on developing conceptual knowledge by heavily relying on qualitative studies, whereas in more static cases, quantitative studies would be favored for testing and validating existing conceptual knowledge.

Fig: 4, Contingent approach to research

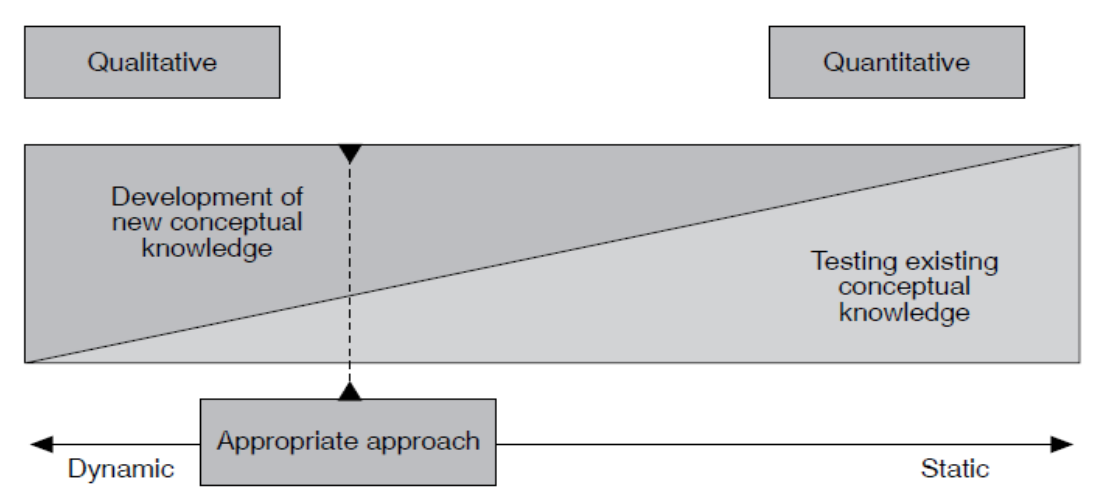

The overall research process may comprise of two interlinked cycles:

1. Knowledge generation and Model creation: Knowledge is generated by formulating new ideas, models and hypotheses. This may be done either by using the quantitative analysis or Case study based approach.

2. Generalization cycles: Generated model may be then tested to determine their relevance for the organization.

\section{Conclusion:}

Significance of the Package Software Services is established by the share it has in the IT services industry. Even after being such an important entity in the IT services portfolio, there has been very little academic work done in this area, specially related to the factors affecting this industry and the challenges around them. Researches on the affecting variable would pave the way for identifying the strategic model for the package software service vendors. This, in turn would be a big area of academic research.

This paper has tried to highlight the key independent variable affecting the strategy of the packaged software services vendors. Intention is to open up the doors for further research on this important topic.

\section{References}

[1]. Jan Damsgaard and Jan Karlsbjerg; Seven Principles for Selecting Software Packages; Communications of the ACM, Vol. 53, No.8, Aug 2010

[2]. Neela AM, Mein J;How to Cut Your IT Maintenance and Support Costs, Gartner, Dec 03

[3]. Patrick Melgarejo, Worldwide Software 2012-2016 Forecast summary, Market Analysis, IDC, 2012

[4]. Gartner, Oct 2013

[5]. Debra Howcroft, Ben Light; The Social Shaping of Packaged Software Selection; Journal of the Association for Information Systems, Vol 11, Issue 3, Mar 2010

[6]. Albert H. Segars, Anthony R. Hendrickson; Value, Knowledge, and the Human Equation: Evolution of the Information Technology Eunction in Modem Organizations; Journal of Labour Research, Vol XXI, Number 3 Summer 2000

[7]. Farheen Altaf and David Schuff; Taking a flexible approach to ASPs; Communications of the ACM, Vol. 53, No. 2, Feb 2010

[8]. Jahangir Karimi, Yash P Gupta, Toni M Somers; Impact of Competitive Strategy and IT Maturity on firm's Strategic Response to Globalization; Journal of Management Information Systems, Spring 1996"

[9]. Debra Howcroft, Ben Light; The Social Shaping of Packaged Software Selection; Journal of the Association for Information Systems, Vol 11, Issue 3, Mar 2010" 
[10]. Rajeev Kumar; Efficient Customization of Software Applications of an Organization; International Journal of Business and Social Science Vol. 4 No. 11; Sep 2013

[11]. Shu Han; Information Technology and Innovation Processes; Rensselaer Polytechnic Institute Troy, New York, Sep 2007

[12]. Varun Grover, Myun Joong Cheon, James T. C. Teng; The Effect of Service Quality and Partnership on the Outsourcing of Information Systems Functions; Journal of Management Information Systems, Vol. 12, No. 4 (Spring, 1996)"

[13]. Anabel Gutierrez, Jorge Orozco and Alan Serrano; Factors affecting IT and business alignment; Journal of Enterprise Information Management Vol. 22 No. 1/2, 2009

[14]. Heather Harreld; Oracle discourages customization of its apps; InfoWorld, Apr 2001

[15]. Paul P. Tallon, Kenneth L. Kraemer, Vijay Gurbaxani; Executives' Perceptions of the Business Value of Information Technology: A Process-Oriented Approach; Journal of Management Information Systems, Vol. 16, No. 4, Spring, 2000

[16]. Yurong Yao, Edward Watson, and Beverly K. Kahn; Application Service Providers: Market and Adoption Decisions; communications of the ACM, Vol. 53, No. 7, July 2010

[17]. Soumitra Dutta and Beñat Bilbao-Osorio; The Global Information Technology Report 2012: Living in a Hyperconnected World; 2012

[18]. Govind Iyer, Sury Ravindran, Philip M. J. Reckers; Procurement of IT Consulting Services and FirmSpecific Characteristics; Journal of the Association for Information Systems Vol. 7 No. 4, April 2006

[19]. Dorothy E. Leidner and Timothy Kayworth; A Review of Culture in Information Systems Research: Toward a Theory of Information Technology Culture Conflict; MIS Quarterly, Vol. 30, No. 2, Jun, 2006

[20]. Gilbert van der Heiden, Frances Karamouzis, Ian Marriott, Ruby Jivan; Magic Quadrant for SAP Application Management Service Providers, Worldwide; Gartner, 3 October 2013

[21]. Mohd Monoar Hussain, Mohd Abu Jahed; Factors Influencing on the adjustment of ERP System during implementation; Global Management Review, Vol 4, Issue 3, May 2010

[22]. Jahangir Karimi, Yash P Gupta, Toni M Somers; Impact of Competitive Strategy and IT Maturity on firm's Strategic Response to Globalization; Journal of Management Information Systems, Spring 1996

[23]. The strategic review; Nasscom (2005)

[24]. Suprateek Sarker, Saonee Sarker, and Arvin Sahaym; Exploring value cocreation in relationship between an ERP vendor and its partners; MIS Quarterly Vol. 36 No. 1 pp. 317-338/March 2012

[25]. Anandhi S. Bharadwaj; A RESOURCE-BASED PERSPECTIVE ON INFORMATIOTNE CHNOLOGYC APABILITY AND FIRM PERFORMANCE; MIS Quarterly Vol.24, No. 1, Mar 2000

[26]. Rainer Feurer and Kazem Chaharbaghi; Researching strategy formulation and implementation in dynamic environments;Benchmarking for QualityManagement \& Technology, Vol. 2 No. 4, 1995, pp. $15-26$ 